One Snowy Owl was shot here last fall, long before the snow came. Perhaps he was a harbinger of that extended cold snap we had during December and January.

And finaliy, the Chickadee, that merry little chirper which is always around to brighten our spirits even on the coldest January morning. To me, they seem to be a northern compensation for the noisy English Sparrow which they superficially resemble. Is there anyone who would not gladly exchange twenty sparrows for one of those chickadees?

Well, it won't be long before the first notes of the Horned Lark come. floating down to us from leaden March skies. Once again we will be eagerly anticipating the first Pintail, the first Meadow Lark, the first Mountain Bluebird. Who among us does not thrill to the age-old, ever-new rhythm of the seasons with its familiar pattern which still permits of intriguing surprises? Up here on the northern fringe of settlement, we'll be waiting, watching and listening for the first spring arrivals.

\title{
"Today I Saw The Dragon-Fly Come From The Wells Where He Did Lie"
}

Hugh McLaughlin, Lewvan

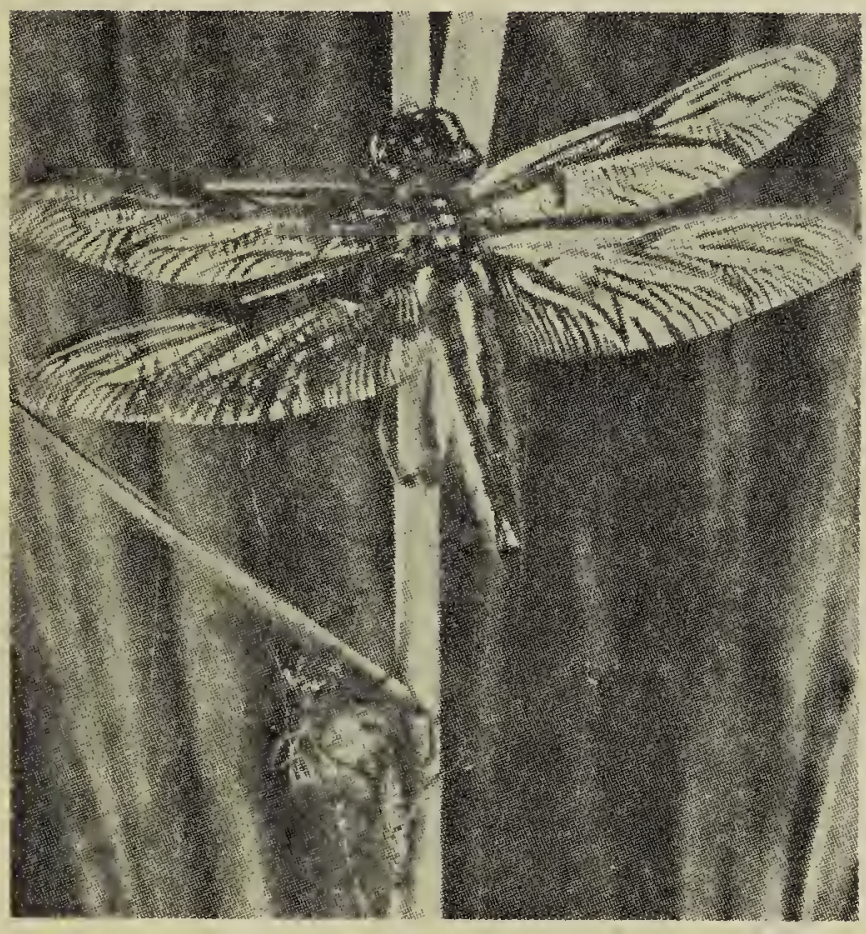

NE spring morning in the early hours while preparing the tractor for work, and noting that the contents of the radiator were down, I sought water at the creek to replenish it. While bending over grass and weeds to fill my pail, I was treated to an assembly line view of the emergence of a dragonfly nymph-a small compressed aquatic insect-a veritable submarine-into the greatly enlarged gauzy-winged adult dragonfly; free flier of the air and sky - a versatile airplane.

The first nymph had but lately emerged from the water and had fastened itself several inches above the surface to a reed. The skin had parted at the back of the thorax and the new creature was literally tumbling backwards out of its skin. The second insect was hanging in stillness to its cast nymphal form, waiting for its body to harden and for tiny sprouts to unroll and spread -waiting for its wings.

The nymphal forms remain clinging to the reeds long after the adult dragonfly takes off-until rain or mechanical disturbances brushes them off. The third insect was experimentally raising and lowering new wings, testing and hardening for its new life. Glancing back again to the first one, the abdomen had grown considerably. It still hung backward in a circle and would soon be able to grasp the reed below, free itself from the limited confines of its aquatic form and await its wings also. However, the demands that sent me here still awaited-this whole process would require an hour or more-so filling the pail I departed

In the aquarium there were several damsel-fly nymphs which are quite like small editions of the dragonfly, although the wings, when at rest, lie together in line with the abdomen instead of at right angles as are the wings of the larger insect. The nymphs have three leaf-like gills attached to the end of the abdomen, which they gently wave back and forth when resting-no doubt to aerate the gills.

One nymph seemed to have grown tired of the water, hovered near the surface and readily climbed out on my finger. As we were leaving the (Continued on page 25) 


\section{Today I Saw the Dragon Fly \\ (Continued from page 17)}

house at the time, the nymph was laid on a box where it quickly became inert-dried out and to all apparances, dead. Returning in an hour it was quite surprising to see the cast form still clinging to the box and the insect, we had thought dead, jubilantly clad in a new blue coat and lacey wings. It was taken outside where it immediately flew off.

Quite as surprising and dramatic was another chapter of this life. An adult damsel-fly lit on the portion of a small rush above the water and then resolutely drew itself "hand by hand" down into the depths. The reason for this irrational appearing behavior soon became apparent. With a probing abdomen the eggs were deposited on the stem-to hatch under water.

Again there is not time to wait and see if the insect would release itself and rise to the surface, and gauzy wings once more take to the air for a few more days in the sun- light with the male who remained aloft. But I rather doubt it. The cycle of life was complete and a tiny discarded craft would disintegrate in the water.

\section{Fox and Rooster Ernest Bishop, Oxbow}

WHILE returning home about ten o'clock one night in early fall, I passed the Peter Ward farm about half a mile wher. I distinctly heard the chortle of a ooster. My curiosity being aroused I stopped the team, and guided by the continued squawks of the rooster I hurried in that direction by the dim light of the moon. When I got close enough, to my surprise, I found the rooster in the grip of a small kit fox who held him by the wattle and was leading him to his den.

The rooster was too heavy for the little fox to carry so he used a wiser and easier method. I was quite close before the fox let go his hold. I caught the bird, nothing worse for his experience, and took him to his owner.

\section{DAMAGE BY DEER EXTENSIVE}

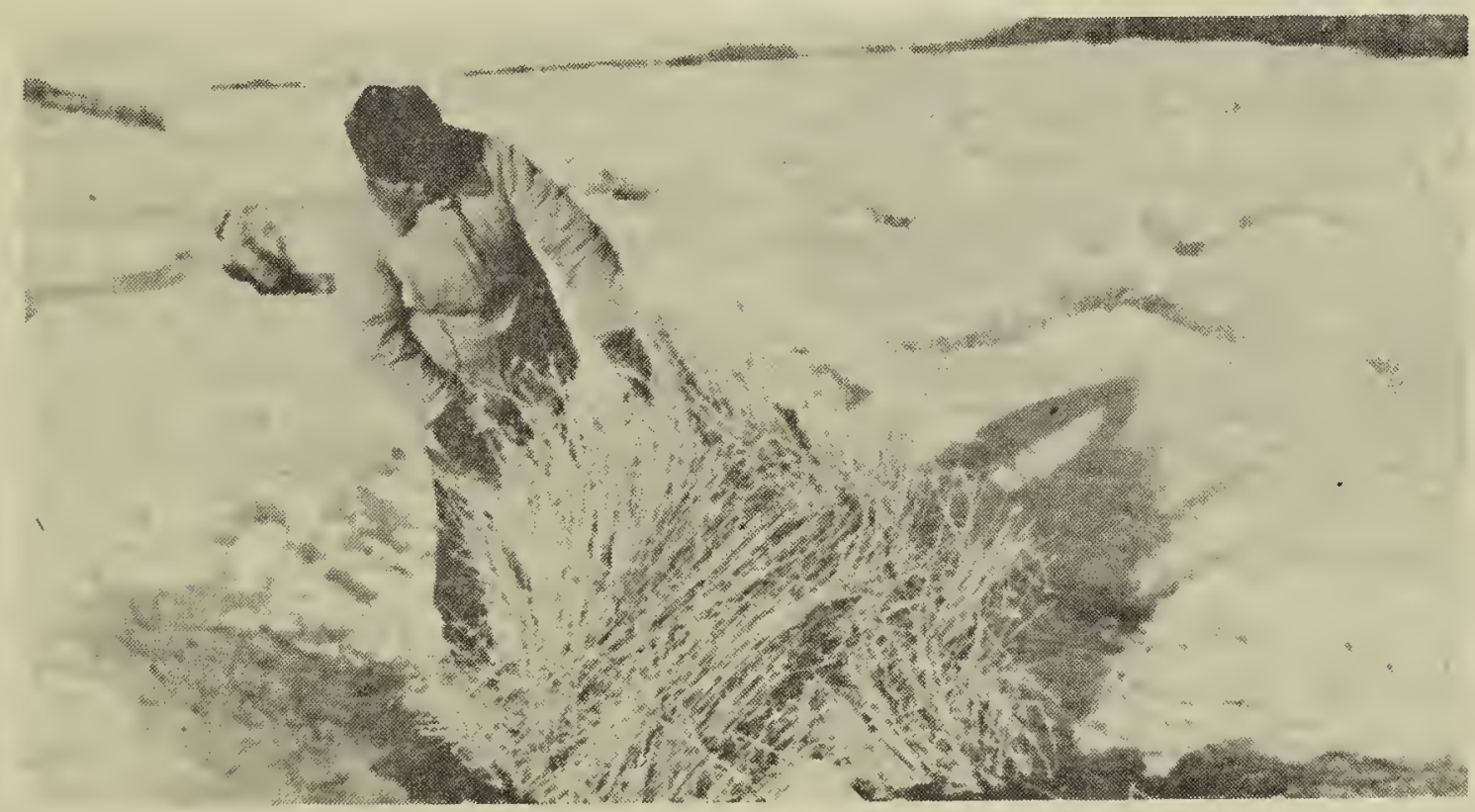

CONSIDERABLE damage was done throughout the winter in various sec4 tions of the province to the numerous fields of grain which are still in swath or in stook. The photograph shows W. A. Brownlee, field officer of the Department of Natural Resources, searching in vain for wheat heads among the snow-covered stooks on the farm of J. R. Kwasnica near Reynaud. Bill explains that in the many areas north of Humboldt, where the snowfall has been heavy, the deer have "yarded up" and have stripped sheaves bare of grain-filled heads. 